\title{
NON-THYROIDAL ILLNESS SYNDROME IN PATIENTS WITH CHRONIC HEPATITIS OF NON-VIRAL ETHIOLOGY
}

\author{
Krystyna Chympoi ${ }^{1}$, Oksana Olinik ${ }^{2}$, Yana Teleki ${ }^{3}$, Nadiia Palibroda ${ }^{4}$, Maryna Patratii ${ }^{5}$
}

\begin{abstract}
:
INTRODUCTION: The effect of hormonal status on the functional state of the liver and endocrine disfunction caused by liver diseases are beyond doubt for most authors.

OBJECTIVES: The aim was to assess thyroid homeostasis in patients with chronic hepatitis and analyze the association between serum thyroid parameters and A/C polymorphism of the deiodinase type 1 (DIO1) gene.

METHODS: The study was conducted on 50 patients with chronic hepatitis and 20 healthy controls. The serum free thyroxine (fT4), free triiodothyronine (fT3) and thyroid stimulating hormone (TSH) were measured and fT3/fT4, fT4/fT3, TSH/fT3, TSH/fT4 ratio, thyroid index and total thyroid index were calculated. The alleles of the polymorphic A/C sites in the DIO1 gene were studied.

RESULT: The level of fT3 was reduced and fT4 level was increased in patients with chronic hepatitis. The fT3/fT4 ratio decreased below the reference range and fT4/fT3 ratio increased by 24,1\%. Elevation of the TSH level and TSH/fT3 ratio were determined. The titres of tyroglobulin autoantibodies and antithyroid peroxidase antibodies significantly exceeded the control values.

It has been established that the carriage of the C-allele DIO1 was associated with an increasing fT3 level and fT3/fT4 ratio, and a decreasing fT4/fT3 ratio and fT4 level, while the presence of A-allele resulted in a decrease in the fT3/fT4 ratio and serum fT3 with the increase in T4 level in patients with chronic hepatitis.

CONCLUSIONS: Chronic hepatitis is accompanied by the development of non-thyroidal illness syndrome. Pathologycal changes in thyroid metabolism are associated with $\mathrm{A} / \mathrm{C}$ polymorphism of the DIO1 gene.
\end{abstract}

UDC Classification: 616.3; DOI: http://dx.doi.org/10.12955/cbup.v6.1266

Keywords: chronic hepatitis, polymorphism, gene, thyroid homeostasis

\section{Introduction}

It is known that more than two-thirds of circulating triiodothyronine (T3) is produced in peripheral tissues by thyroxine (T4) deiodinating. De Vries et al. (2015) write about extra-thyroidal conversion of T4 to T3, which in healthy humans accounts for more than $80 \%$ of T3 production, is carried out in the liver, kidneys, and the pituitary by means of three iodothyronine deiodinases. As Yu \& Koenig (2006) researched that special attention should be paid to hepatic deiodinase 1 (DIO1), which not only catalyzes the conversion of $\mathrm{T} 4$ to $\mathrm{T} 3$, but also is a selenium-containing protein that interacts with two other substrates - iodothyronines and reduced glutathione.

It has been shown that the peripheral conversion of $\mathrm{T} 4$ into $\mathrm{T} 3$, which occurs in the liver, plays an important role in regulating the concentration of these hormones in serum and in the optimization of thyroid status while the physiological state of the organism is changing. Thus, the state of T4 to T3 liver biotransformation is a "modulating factor" for the functional state of the thyroid gland due to changes in the quantity of active T3 in the blood.

Lee \& Farwell (2016) claim that detection of typical changes in thyroid-related hormone concentrations that are not caused by a primary abnormality in the thyroid function but is a result of damage to other organs and systems has become the basis for the formation of the "non-thyroidal illness syndrome (NTIS)' concept. The alternative terms such as 'Euthyroid sick syndrome', "Euthyroid pathological syndrome" and "Low T3 syndrome" were widely used in the past. However, NTIS is not a manifestation of hypothyroidism, but is determined by the severity of the underlying disease.

Aim: to assess thyroid homeostasis in patients with chronic hepatitis of non-viral etiology and to investigate the association between serum thyroid parameters and $\mathrm{A} / \mathrm{C}$ polymorphism of the deiodinase type 1 (DIO1) gene in these patients.

Material and Methods of Investigation. Of 50 patients with chronic hepatitis in this study, 27 (54.0\%) were men. The patients were aged 38-64 years old with a mean age of $49.6 \pm 8.59$ years. The mean

\footnotetext{
${ }^{1}$ Higher education institution of Ukraine «Bukovinian State Medical University», chimpoik@ gmail.com

${ }^{2}$ Higher education institution of Ukraine «Bukovinian State Medical University», olinoks@ gmail.com

${ }^{3}$ Higher education institution of Ukraine «Bukovinian State Medical University», jana_med@ua.fm

${ }^{4}$ Higher education institution of Ukraine «Bukovinian State Medical University», nadya.palibroda@gmail.com

${ }^{5}$ Higher education institution of Ukraine «Bukovinian State Medical University», patratii@mail.ua
} 
duration of disease was reported as $6.0 \pm 2.10$ (range: 1-15) years. Of the patients, $25(50 \%)$ had mild active hepatitis and the other $25(50 \%)$ had moderately active disease. Mean age of the 20 healthy controls was $52.2 \pm 12.15$ years, of whom $13(65.0 \%)$ were male and $7(35.0 \%)$ were female.

The study was performed in the Gastroenterology Department of the Chernivtsi Regional Clinical Hospital, Ukraine.

The diagnosis of hepatitis was based on complaints, anamnesis, physical examination, laboratory analysis: general blood count, urinalysis, liver function tests (alanine aminotransferase (ALT), aspartate aminotransferase (AST), $\gamma$-glutamiltransferaze (GGT), alkaline phosphatase (AP), thymol test), blood urea, creatinine, serum markers of hepatitis B and C viruses. Additional studies were also performed (ultrasound examination of the abdominal cavity, upper endoscopy). The activity of hepatitis was evaluated by clinical and biochemical parameters (ALT, AST, thymol test, bilirubin).

The thyroid homeostasis was evaluated by using 'thyroid function tests', measurement of serum free thyroxine (fT4), free triiodothyronine (fT3) and thyroid stimulating hormone (TSH) by means of ELISA («IMUNOFA-TTG», «IEA-f $\mathrm{T}_{3} » \mathrm{Ta}$ «IEA-f $\mathrm{T}_{4}-1 »$, «Immunotech»).

To evaluate the function of the pituitary-thyroid axis, the author calculated fT3/fT4, fT4/fT3, TSH/fT3, TSH/fT4 ratio, thyroid index and total thyroid index.

Autoimmune diseases of the thyroid gland were excluded by the determination of serum antibodies to thyroglobulin (AT-TG) and antibodies to thyroid peroxidase (anti-TPO) by using ELISA kits «IEA-ABTG-1», «IMMUNOEA-AB-TPO» («Immunotech»).

The alleles of the polymorphic A/C sites in the DIO1 gene were studied by extracting of genomic DNA from the peripheral blood leukocytes with subsequent amplification of the polymorphic site using a polymerase chain reaction («Amply-4L», «Biocom», Moscow) with individual temperature program for gene primers. DNA extraction was carried out using the «DNA-sorb-B» variant 100 (FGUN CNIIE, Russia) according to the instructions. The purified DNA was stored at minus $20 \pm 2^{\circ} \mathrm{C}$. Samples for PCR were prepared using «AmpliSens-200-1» (FGUN CNIIE, Russia). For the discrimination of the alleles of the DIO1 gene Bcl I endonuclease restriction («SibEnzim», Russia) was used.

Table 1: Primer oligonucleotide sequences used for polymerase chain reaction in identification of DIO1 A/C gene polymorphism

\begin{tabular}{|r|c|l|r|}
\hline Gene & $\begin{array}{c}\text { Gene location on } \\
\text { the chromosome }\end{array}$ & Primer & Primer oligonucleotide sequences \\
\hline \multirow{2}{*}{ DIO1 } & $1 \mathrm{p} 33-\mathrm{p} 32$ & Direct & 5'-GAACTTGATGTGAAGGCTGGA-3' \\
\cline { 2 - 4 } & Reverse & 5'-TAACCTCAGCTGGGAGTTGTTT-3' \\
\hline Source: Authors
\end{tabular}

Depending on the distribution of $\mathrm{DIOl} \mathrm{A/C} \mathrm{gene} \mathrm{polymorphism} \mathrm{the} \mathrm{patients} \mathrm{were} \mathrm{divided} \mathrm{into} \mathrm{three}$ groups: AA genotype carriers - 17 patients, the AC genotype carriers - 24 and the CCgenotype carriers -9 patients.

Results of the Investigation. It was determined that patients with chronic hepatitis showed a decrease in their fT3 levels by $12.1 \%(\mathrm{p}<0.01)$ compared to the healthy controls (Table 2), although it was still within the reference range in the majority of patients with only $6 \%$ showing fT3 levels below the reference range. Besides, the fT4 level was raised by $15.1 \%(\mathrm{p}<0.01)$ compared to the control group with only 3 patients showing a fT4 level above the reference range, whereas in 1 patient it was less than normal.

These changes were probably caused by impaired activity of the deiodinase type 1 and inhibited the conversion rate of fT 4 to fT 3 . The theory might be confirmed by the significantly reduced fT3/fT 4 ratio (by $21.6 \%, \mathrm{p}<0.001$ ), that decreased below the reference range in $78 \%$ of patients with chronic hepatitis. At the same time, the fT4/fT3 ratio increased by $24.1 \%(\mathrm{p}<0.001)$ compared to the healthy controls, which can be attributed to the non-thyroidal illness syndrome in these patients.

We found that the $\mathrm{fT}_{3} / \mathrm{fT}_{4}$ ratio was below the reference range in $78 \%$ of patient with chronic hepatitis whereas in $16 \%$ it was within normal range and it even increased in $6 \%$ of cases. An increase of the TSH level by $28.7 \%$ compared to the healthy controls $(\mathrm{p}<0.05)$ was determined in patients with chronic hepatitis, although as many as $94 \%$ of patients exhibited TSH concentrations within reference range of 
0.3-4.0 mU/l. High levels of TSH was found in $4 \%$ of patients while low levels were in $2 \%$. The $\mathrm{TSH} / \mathrm{fT} 3$ ratio increased by $45.7 \%$ compared to the healthy controls $(\mathrm{p}<0.05)$, but the TSH/fT4 ratio, thyroid index and total thyroid index did not significantly change in the case of chronic hepatitis $(\mathrm{p}>0.05)$. Consequently, the pituitary responds to a decrease in fT3 by increasing TSH synthesis on the basis of feedback.

In general, the results can be considered as inhibition of thyroid function in patients with chronic hepatitis, which, in our opinion, is primarily due to the violation of peripheral deiodination of thyroid hormones.

To determine the autoimmune thyroid pathology, the titres of tyroglobulin autoantibodies and antithyroid peroxidase antibodies were determined, that exceeded the normal values in 3 patients $(6.0 \%)$. The titres of AT-TG and anti-TPO significantly exceeded the control group values in 1.9 and 2.6 thresholds respectively ( $\mathrm{p}<0.001)$, indicating a risk of autoimmune thyroid disease in patients with chronic hepatitis (Table 2).

A Pearson's correlation coefficient was used to examine the association between the thyroid abnormalities and the degree of liver damage by analyzing the links between fT3/fT4 and the total blood bilirubin ( $\mathrm{r}=-0.373, \mathrm{p}<0.05)$, ALT activity $(\mathrm{r}=-0.406, \mathrm{p}<0.05)$.

Consequently, the results of the correlation analysis indicate the association between liver function and thyroid homeostasis.

\begin{tabular}{|c|c|c|}
\hline \multicolumn{3}{|c|}{ Table 2: Thyroid homeostasis in patients with chronic hepatitis of non-viral etiology $(\mathrm{M} \pm \mathrm{m})$} \\
\hline \multirow{4}{|c|}{ Parameter } & $\begin{array}{c}\text { Controls } \\
(\mathbf{n}=\mathbf{2 0})\end{array}$ & $\begin{array}{c}\text { Patients with chronic hepatitis } \\
(\mathbf{n}=\mathbf{5 0})\end{array}$ \\
\hline TSH $(\mu \mathrm{U} / \mathrm{l})$ & $1.78 \pm 0.162$ & $2.29 \pm 0.139 \quad \mathrm{p}<0,05$ \\
\hline $\mathrm{fT} 4(\mathrm{pmol} / \mathrm{l})$ & $15.88 \pm 0.894$ & $18.27 \pm 1.142 \quad \mathrm{p}<0,001$ \\
\hline $\mathrm{fT} 3(\mathrm{pmol} / \mathrm{l})$ & $5.47 \pm 0.326$ & $4.81 \pm 0.103 \quad \mathrm{p}<0,01$ \\
\hline fT3/fT4 & $0.37 \pm 0.029$ & $0.29 \pm 0.010 \quad \mathrm{p}<0,05$ \\
\hline fT4/fT3 & $3.19 \pm 0.237$ & $3.76 \pm 0.118 \quad \mathrm{p}<0,05$ \\
\hline TSH/fT3 & $0.35 \pm 0.040$ & $0.51 \pm 0.022 \quad \mathrm{p}<0,05$ \\
\hline TSH/fT4 & $0.12 \pm 0.011$ & $0.14 \pm 0.012 \quad \mathrm{p}>0.05$ \\
\hline Thyroid index & $13.78 \pm 1.301$ & $12.90 \pm 0.625 \quad \mathrm{p}>0,05$ \\
\hline Total thyroid index & $247.60 \pm 13.610$ & $228.10 \pm 9.816 \quad \mathrm{p}>0.05$ \\
\hline AT-TG $(\mathrm{U} / \mathrm{ml})$ & $26.29 \pm 2.446$ & $49.61 \pm 4.206$ \\
\hline anti-TPO $(\mathrm{U} / \mathrm{ml})$ & $11.94 \pm 1.067$ & $31.04 \pm 1.062$ \\
\hline
\end{tabular}

Notes: $\mathrm{n}$ - number of observations; $\mathrm{p}$ - comparing with control group.

Source: Authors

The dependence of thyroid homeostasis on the A/C polymorphism of the DIO1 gene in patients with chronic hepatitis is shown in Table 3.

The study did not reveal an association between the genotypes of the DIO1 gene and the level of TSH in serum.

It was found that the $\mathrm{fT} 3$ level was higher in the $\mathrm{CC}$ variant than in the AA and $\mathrm{AC}$ variants by $32.7 \%$ $(\mathrm{p}<0.001)$ and $25.1 \%(\mathrm{p}<0.01)$ respectively.

We report in this study that fT4 in patients with homozygous carriage of the A-allele of the DIO1 gene was significantly higher in patients with the $\mathrm{CC}$ variant $(+37.4 \%, \mathrm{p}<0.05)$.

Concerning the fT3/fT4 ratio, it was in 1.5 times higher in the AA variant $(\mathrm{p}<0.05)$ and 1.2 times higher in AC carriers. The fT4/tT3 ratio also varied depending on the polymorphism of the DIO1 gene. In patients with the AA-genotype it was in 1.7 times $(\mathrm{p}<0.05)$ higher than in the $\mathrm{CC}$ variant and 1.2 times (p> 0.05) higher than in the AC variant.

Similar patterns are established with respect to the TSH/fT3 ratio.

In addition, patients with the $\mathrm{CC}$ variant showed a higher thyroid index and total thyroid index than the AA variant (2.0 and 1.3 times respectively).

We report in this study that the CC variant is associated with the elevation of fT3/fT4, fT3 as well as a decrease in T4, while the AA genotype is associated with a decrease in the fT3/fT4, T3, and a rise in T4. 


\begin{tabular}{|c|c|c|c|c|}
\hline \multicolumn{5}{|c|}{$\begin{array}{l}\text { Table 3: The dependence of th } \\
\text { with chronic hepatitis }(\mathrm{M} \pm \mathrm{m})\end{array}$} \\
\hline \multirow[b]{2}{*}{ Parameter } & \multirow[b]{2}{*}{$\begin{array}{l}\text { Controls } \\
(n=20)\end{array}$} & \multicolumn{3}{|c|}{ DIO1 genotype, $n=50$} \\
\hline & & $\begin{array}{c}\mathrm{AA} \\
\mathrm{n}=17\end{array}$ & $\begin{array}{c}\mathrm{AC} \\
\mathrm{n}=24\end{array}$ & $\begin{array}{c}\mathrm{CC} \\
\mathrm{n}=9\end{array}$ \\
\hline $\mathrm{TSH}(\mu \mathrm{U} / \mathrm{l})$ & $1.78 \pm 0.162$ & $\begin{array}{c}2.53 \pm 0.157 \\
\mathrm{p}_{1}<0.001\end{array}$ & $\begin{array}{c}2.37 \pm 0.292 \\
\mathrm{p}_{1}<0.05 \\
\mathrm{p}_{2}>0.05\end{array}$ & $\begin{array}{c}2.21 \pm 0.102 \\
\mathrm{p}_{1}<0.001 \\
\mathrm{p}_{2}>0.05 \\
\mathrm{p}_{3}>0.05\end{array}$ \\
\hline fT4 (pmol/l) & $15.88 \pm 0.894$ & $\begin{array}{c}21.01 \pm 1.359 \\
\mathrm{p}_{1}<0.05\end{array}$ & $\begin{array}{c}18.16 \pm 1.207 \\
\mathrm{p}_{1}<0.05 \\
\mathrm{p}_{2}>0.05\end{array}$ & $\begin{array}{c}15.29 \pm 1.516 \\
\mathrm{p}_{1}>0.05 \\
\mathrm{p}_{2}<0.05 \\
\mathrm{p}_{3}>0.05\end{array}$ \\
\hline fT3 (pmol/l) & $5.47 \pm 0.326$ & $\begin{array}{c}4.37 \pm 0.234 \\
\mathrm{p}_{1}<0.05\end{array}$ & $\begin{array}{c}4.86 \pm 0.240 \\
\mathrm{p}_{1}>0.05 \\
\mathrm{p}_{2}>0.05\end{array}$ & $\begin{array}{c}6.49 \pm 0.134 \\
\mathrm{p}_{1}<0.05 \\
\mathrm{p}_{2}<0.001 \\
\mathrm{p}_{3}<0.01\end{array}$ \\
\hline fT3/fT4 & $0.37 \pm 0.029$ & $\begin{array}{c}0.26 \pm 0.018 \\
\mathrm{p}_{1}<0.01\end{array}$ & $\begin{array}{c}0.32 \pm 0.012 \\
\mathrm{p}_{1}<0.05 \\
\mathrm{p}_{2}>0.05\end{array}$ & $\begin{array}{c}0.39 \pm 0.017 \\
\mathrm{p}_{1}>0.05 \\
\mathrm{p}_{2}<0.05 \\
\mathrm{p}_{3}<0.05\end{array}$ \\
\hline fT4/fT3 & $3.19 \pm 0.337$ & $\begin{array}{c}5.16 \pm 0.347 \\
\mathrm{p}_{1}<0.05\end{array}$ & $\begin{array}{c}4.28 \pm 0.235 \\
\mathrm{p}_{1}<0.05 \\
\mathrm{p}_{2}>0.001\end{array}$ & $\begin{array}{c}3.11 \pm 0.101 \\
\mathrm{p}_{1}>0.05 \\
\mathrm{p}_{2}<0.05 \\
\mathrm{p}_{3}>0.05\end{array}$ \\
\hline TSH/fT3 & $0.35 \pm 0.04$ & $\begin{array}{c}0.71 \pm 0.089 \\
\mathrm{p}_{1}<0.001\end{array}$ & $\begin{array}{c}0.58 \pm 0.063 \\
\mathrm{p}_{1}<0.05 \\
\mathrm{p}_{2}>0.05\end{array}$ & $\begin{array}{c}0.41 \pm 0.029 \\
\mathrm{p}_{1}>0.05 \\
\mathrm{p}_{2}<0.05 \\
\mathrm{p}_{3}>0.05\end{array}$ \\
\hline TSH/fT4 & $0.12 \pm 0.011$ & $\begin{array}{c}0.16 \pm 0.021 \\
\mathrm{p}_{1}>0.05\end{array}$ & $\begin{aligned} 0.15 \pm 0.013 \\
\mathrm{p}_{1}>0.05 \\
\mathrm{p}_{2}>0.05\end{aligned}$ & $\begin{aligned} 0.11 \pm 0.022 \\
\mathrm{p}_{1}>0.05 \\
\mathrm{p}_{2}>0.05 \\
\mathrm{p}_{3}>0.05\end{aligned}$ \\
\hline Thyroid index & $13.78 \pm 1.301$ & $\begin{array}{c}9.78 \pm 0.834 \\
\mathrm{p}_{1}<0.05\end{array}$ & $\begin{array}{c}14.11 \pm 2.410 \\
\mathrm{p}_{1}>0.05 \\
\mathrm{p}_{2}>0.05\end{array}$ & $\begin{array}{c}19.84 \pm 2.203 \\
\mathrm{p}_{1}<0.001 \\
\mathrm{p}_{2}<0.001 \\
\mathrm{p}_{3}>0.05\end{array}$ \\
\hline Total thyroid index & $247.60 \pm 13.61$ & $\begin{array}{c}210.6 \pm 12.19 \\
\mathrm{p}_{1}<0.05\end{array}$ & $\begin{array}{c}233.1 \pm 11.07 \\
\mathrm{p}_{1}>0.05 \\
\mathrm{p}_{2}>0.05\end{array}$ & $\begin{aligned} 269.7 \pm 16.34 \\
\mathrm{p}_{1}>0.05 \\
\mathrm{p}_{2}<0.05 \\
\mathrm{p}_{3}>0.05\end{aligned}$ \\
\hline AT-TG (U/ml) & $26.29 \pm 2.446$ & $\begin{array}{c}57.08 \pm 6.184 \\
\mathrm{p}_{1}<0.001\end{array}$ & $\begin{array}{c}53.01 \pm 5.509 \\
\mathrm{p}_{1}<0.001 \\
\mathrm{p}_{2}>0.05\end{array}$ & $\begin{array}{c}50.16 \pm 6.186 \\
\mathrm{p}_{1}<0.001 \\
\mathrm{p}_{2}>0.05 \\
\mathrm{p}_{3}>0.05\end{array}$ \\
\hline \multicolumn{5}{|c|}{$\begin{array}{l}\text { Notes: } n \text { - number of observations; } \mathrm{p} 1 \text { - comparing with control group; } \mathrm{p} 2 \text { - comparing with AA variant; } \mathrm{p} 3 \text { - } \\
\text { comparing with AC variant. }\end{array}$} \\
\hline Source: Authors & & & & \\
\hline
\end{tabular}

\section{Discussion}

Thyroid homeostasis changes identified in patients with chronic hepatitis are probably caused by impaired DIO 1 activity resulted in low conversion of T4 into more active fT3. The association between thyroid parameters and $\mathrm{A} / \mathrm{C}$ polymorphism of the deiodinase type 1 gene in these patients was determined. Increased serum T4 can be explained by a decrease in absorption of this hormone by a damaged liver, since it is known that $80 \%$ of intracellular T4 is located in hepatocytes. Decreased serum T3 ("syndrome of low T3"), probably is caused by a reduction of peripheral conversion of T4 into T3. The theory might be confirmed by a significantly reduced fT3/fT4 ratio (by $21.6 \%, \mathrm{p}<0.001$ ), that decreased below the reference range in $78 \%$ of patients with chronic hepatitis. At the same time, the 
fT4/fT3 ratio increased by $24.1 \%(\mathrm{p}<0.001)$ compared to the healthy controls, that can be attributed to the non-thyroidal illness syndrome in these patients.

The TSH level in serum is a well known screening test for the evaluation of thyroid homeostasis as its synthesis and secretion are the central links in the mechanism of thyroid function regulation and peripheral metabolism of thyroid hormones.

Increasing TSH level and TSH/fT3 ratio were found in patients with chronic hepatitis. Consequently, the pituitary reacts to impaired thyroid metabolism through the increase in thyroid function on the basis of feedback.

Despite the fact that the titers of anti-thyroid antibodies in patients with chronic hepatitis do not meet the basic criteria for autoimmune thyroiditis, these results indicate an increased risk of autoimmune thyroid disease in these patients.

Non-thyroidal illness syndrome that was diagnosed in patients with chronic hepatitis (thyroid dysfunction syndrome) is a complex of typical changes in thyroid-related hormone concentrations that is not caused by a primary abnormality in thyroid functions but is a result of the liver damage. The formation of NTIS is manifested, first of all, by disorders of the peripheral metabolism of thyroid hormones as a result of endogenous intoxication, which is common in chronic hepatitis as Eshraghian \& Jahromi (2014) point out.

Bano et al. (2016) describe that the liver carries out specific functions related to the transport and metabolism of thyroid hormones in addition to the leading role in deiodinating of thyroid hormones resulted in the formation of their more active and inactivated forms. It is proven that T4 and T3 transport through the hepatocyte membrane is an active energy-dependent process. In the liver, a series of plasma proteins that bind lipophilic thyroid hormones are synthesized, resulting in a large, rapidly changing pool of hormones in circulation. Consequently, the concentration of thyroid hormones in the blood plasma depends on the transport speed and deiodinase activity. Thus, the thyroid status depends not only on the secretion of hormones, but also on the level of thyroid hormone metabolism, T3 transport to nuclear receptors, and the distribution and functional ability of thyroid receptors. Thus, the state of thyroid homeostasis is directly dependent on liver function.

\section{Conclusions}

Thyroid disfunction, characterized by decreased serum fT3 level, fT3/fT4 ratio and increased serum TSH and fT4 levels, is common in patients with chronic hepatitis. The determined changes in thyroidrelated hormone status in patients with chronic hepatitis show the formation of Non-thyroidal illness syndrome in patients as a result of low conversion of T4 into fT3, probably due to impaired liver deiodinase activity. The presence of the AA-genotype of the type 1 deiodinase gene in patients with chronic hepatitis is associated with a decrease in free triiodothyronine level in serum, a ratio of free triiodothyronine to free thyroxine and an increase in serum free thyroxine. A/C polymorphism of the DIO1 gene does not affect the titres of antibodies to the thyroid gland tissue in patients with chronic diffuse liver disease.

\section{References}

Bano A, Chaker L, Plompen E.P., Hofman A, Dehghan A, Franco O.H., Janssen H.L., Darwish S. and Peeters R.P. (2016) Thyroid Function and the Risk of Nonalcoholic Fatty Liver Disease: The Rotterdam Study. J. Clin. Endocrinol. Metab.101(8), 3204-3211.

de Vries E.M., Fliers E, Boelen A. (2015) The molecular basis of the non-thyroidal illness syndrome. J. Endocrinol. 225 (3), 67-81.

Eshraghian A, Jahromi A.H. (2014) Non-alcoholic fatty liver disease and thyroid dysfunction: A systematic review. World J. Gastroenterol. 20 (25), 8102-8109.

Lee S, Farwell A.P. (2016) Euthyroid Sick Syndrome. Compr. Physiol. 6 (2), 1071-1080.

Yu J, Koenig R.J. (2006) Induction of type 1 iodothyronine deiodinase to prevent the nonthyroidal illness syndrome in mice. Endocrinology. 147 (7), 3580-3585. 